\title{
Importance of field operations for reducing red palm weevil (RPW) infestation on date palm
}

\author{
Mohamed Ben Salah \\ Development of Sustainable Date Palm Production \\ Systems in the GCC Countries of the Arabian Peninsula-ICARDA Project, Oman. Email: m.ben-salah@cgiar.org
}

\begin{abstract}
Ben Salah, M. 2019. Importance of field operations for reducing red palm weevil (RPW) infestation on date palm. Arab Journal of Plant Protection, 37(2): 159-162.

Date palm tree is known to be very sensitive to field operations. The production and health of the tree are relative to the attention of the growers. Several field operations, including the choice of offshoots, spacing, fertilization, irrigation, fruit thinning, leaf pruning, and harvesting are important field practices. Cultivation operations, if well conducted, can reduce pest infestation on date palm tree and fruits, ameliorate the health of date palm tree and its production. It is essential to adopt the best practices to avoid many fungal and pest's infestations and reduce the loss of date palm production up to 30-40\%. Red Palm Weevil (Rhynchophorus ferrugineus) is spread rapidly from East to West during 30 last years and was reported in several date-producing countries in the region. Studies carried out in date palm cultivation area confirmed that the date palm farming practices adopted, the variety planted, method of irrigation (flood/drip), palm density, crop and field sanitation, frond pruning, and offshoot removal, significantly impacted the establishment and subsequent infestation level due to red palm weevil on date palm. Keywords: Date palm, pest management, best agricultural practices, RPW.
\end{abstract}

\section{Introduction}

Date palm still playing a major role in the agriculture activity and food production in dry areas. Many challenges are facing date palm: Climate change, environmental stress (soil fertility, water and soil salinity) and the invasive pests (ICARDA, 2016). Red Palm Weevil (Rhynchophorus ferrugineus) is one of the major pests of date palm, spread rapidly in several date-producing countries and Canary palms (Phoenix canariensis), especially in the Mediterranean basin.

RPW was spread further mainly through infested ornamental gardening and farming planting transported offshoots. Cultivation operations, if well conducted can reduce the infestations of date palm tree, ameliorate the health of the palms and reduce the loss of date palm production around $30-40 \%$. When no precautions were observed when selecting offshoots, close spacing, no proper fertilization use, shortage in irrigation water, no fruit thinning and leaves pruning, and lack of proper harvesting are considered poor field practices. This paper summarizes the importance of best agricultural practices to reduce date palm tree and dates infestation by pests, especially RPW.

\section{Choice and Handling of Offshoots}

The main way to propagate date palm is still by offshoots. Major dangerous infestations are related to the origin of offshoots. RPW is an example of pests that spread through plants exchange and transfer between regions in the same country and inter-countries and continents (Faleiro et al., 2006).

When establishing date palm plantations, it is important to pay attention to the origin of offshoots. One should ensure that they are free from pests, especially RPW. When there is doubt about pest's presence, it is necessary to disinfest the offshoots. National programs should implement an easy and fast exchange of plant genetic material without any risk of diseases and pests spread. Many authors reported that the exchange of offshoots is the main responsible way of spreading RPW in North Africa and the Mediterranean region (Figure 1).

\section{Planting Density}

The most traditional plantations in Middle East and North Africa are not widely spaced and not planted in straight lines. The practice of removing offshoots from the date palm mother stem is not always well-practiced. This complicates cultivation and protection interventions and facilitate infestation by pests, especially RPW. In well managed orchards, offshoots are removed at 3-4 years' age to maintain single stem trees.

Spacing and properly designed plantations can facilitate cultural practices, mechanization and spraying pesticides to combat pests when needed. When establishing modern farms, it is preferable to plant offshoots in straight rows and maintain a minimum $8 \times 8$ meters spacing, that is 156 palm trees per hectare (Ben Salah, 1999).

\section{Cultivation Operations}

Studies carried out in date palm cultivation area proved that farming practices adopted, the method of irrigation (flood/drip), plants density, crop and field sanitation, frond pruning, and offshoot removal, etc. have significant reduction in infestation of pests, especially RPW in the date palm plantations (Ben Salah, 2018). 


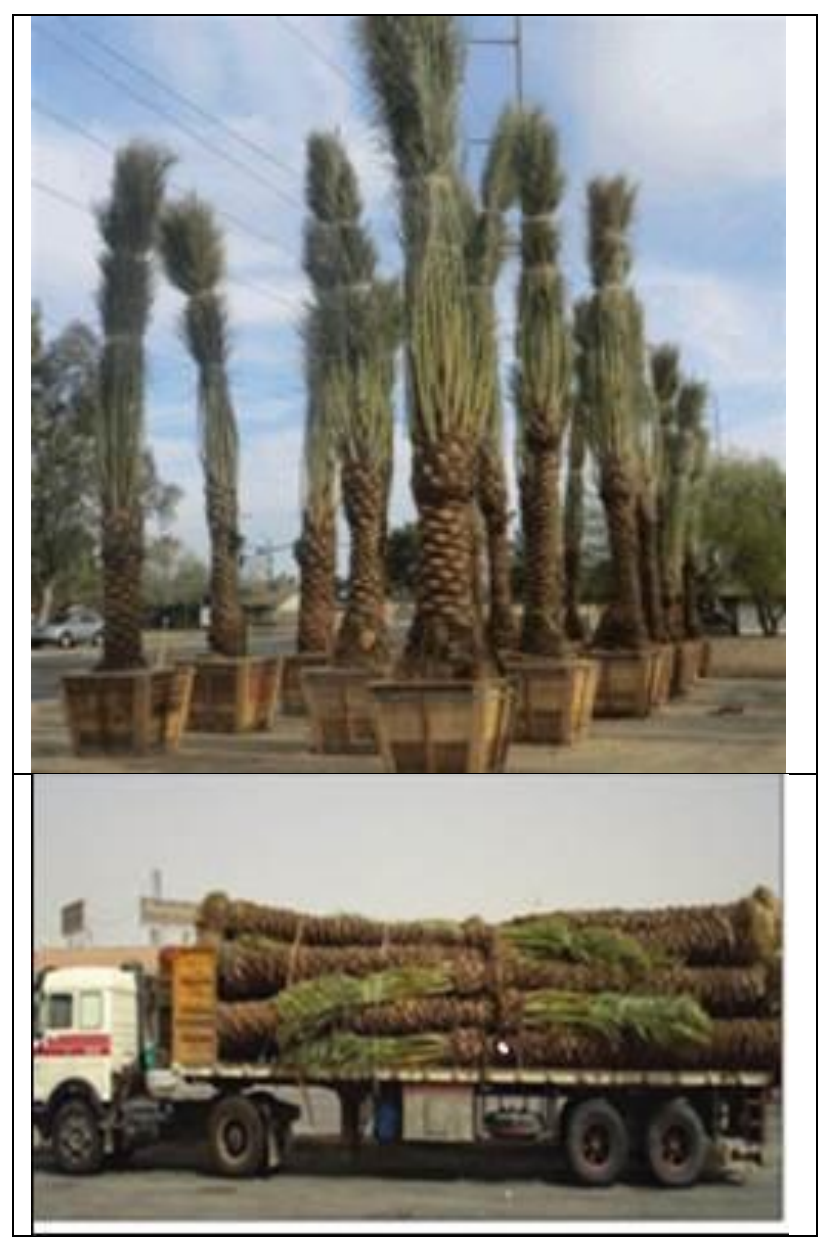

Figure 1. Offshoots handling and transportation.

\section{Irrigation and Fertilization}

Irrigation is necessary to date palm for optimal vegetative growth and good fruit quality. More water quantity is necessary in many places where the subsoil water is too saline for date palm, and irrigation keep down the salt when the surface irrigation water is soft and plentiful. However, surface irrigation techniques (flood water supply) can affect the date palm trunk and facilitate hibernation of pests.

Flood irrigation is still carried out in major plantations. This practice facilitate infestation by pests and fungi carried by irrigation water. It facilitates also the RPW entry in the date palm trunk. Frequent watering causes offshoot damage and create adequate conditions for pests to survive in the bottom of the date palm stem (Liebenberg and Zaid, 2002).

New sub-surface irrigation methods are developed and have the advantage of saving water resources. Many subsurface techniques are being investigated. The sub subsurface irrigation can avoid the development of weeds in the base of date palm tree and hibernation of pests, thus improving the date palm trunk health (Dewidar et al., 2016) (Figure 2).

Fertilization is necessary for the date palm to improve over-all plant growth, extended leaf longevity and improves date palm yield. Nutrient deficiency can affect the date palm tree growth and symptoms can be easily observed. Good date palm health can reduce the infestations by insects and pests. It is advisable to apply the organic and phosphate fertilizers as one application deep in the soil. Nitrogen and potassium elements should be divided into 3-4 applications, starting at the beginning of flowering season (January-February) and repeated every 2 months thereafter until date harvesting.

Organic fertilizer is one of the most important sources of infection when it is not thermally treated. Insect eggs and larvae can be carried by fertilizer. Organic fertilizer must be thermally treated to ensure its safety from the pest's larvae and eggs. It is recommended to add $5-10 \mathrm{~kg} /$ tree annually. This quantity can vary depending on soil fertility (El Bekr, 1972; Klein and Zaid, 2002).

When adding mineral fertilizer, it is very important to be mix it properly with the soil. Some farmers broadcast fertilizers on soil surface and leaving it without mixing, which leads to great loss of nutrients through volatilization and percolation. Proper fertilization with major and minor elements can produce healthy and productive plants and reduce pest's attack.

\section{Date palm Crown Operations}

Pollination - Date palm trees are dioecious having male and female separate plants. Artificial pollination is essential for the completion of date palm fruit setting for optimum production. The male flower produces pollen, which is transferred to the inflorescence of the receptive female plant. Developed techniques for dry and liquid pollination can help to control the date palm health and avoid transfer of pests via pollination.

Dry and liquid pollination use hand and machine dusters or spraying machine from ground surface, without climbing the tree (Figure 3). Both techniques use extracted pollen (Ben Salah and El Marzooqi, 2000; Shabana et al., 1985). Extracting pollen from male bunches can reduce the infestation of the bunch and can reduce the transport of insects from the male (pollinator) to the female date palm tree. In dry pollination, pollen is mixed by talc or flour. In liquid pollination, pollen is mixed with water. Both methods can reduce pests transport and bunches infestation.

Date palm liquid pollination recently developed proved to be a good technique for improving fruit setting rate, save time, reduce cost and consequently improve dates quality. In addition, using liquid pollination technology reduce labor costs and risk of laborers climbing accidents. The economic evaluation of the liquid pollination shows reduction of more than $50 \%$ of the operation cost. The technique is being successfully disseminated to all GCC countries within the project (Ben Salah and Al-Raissi, 2017).

The other advantage of liquid pollination is reducing the risk of transmission of pests carried by the male bunch to the female date palm tree, especially by inflorescence rot caused by Mauginiella scattae Cav., Fusarium moniliforme and Thielaviopsis paradoxa. The liquid pollination can be improved using pollen extraction devices which help adopting the new technology. 


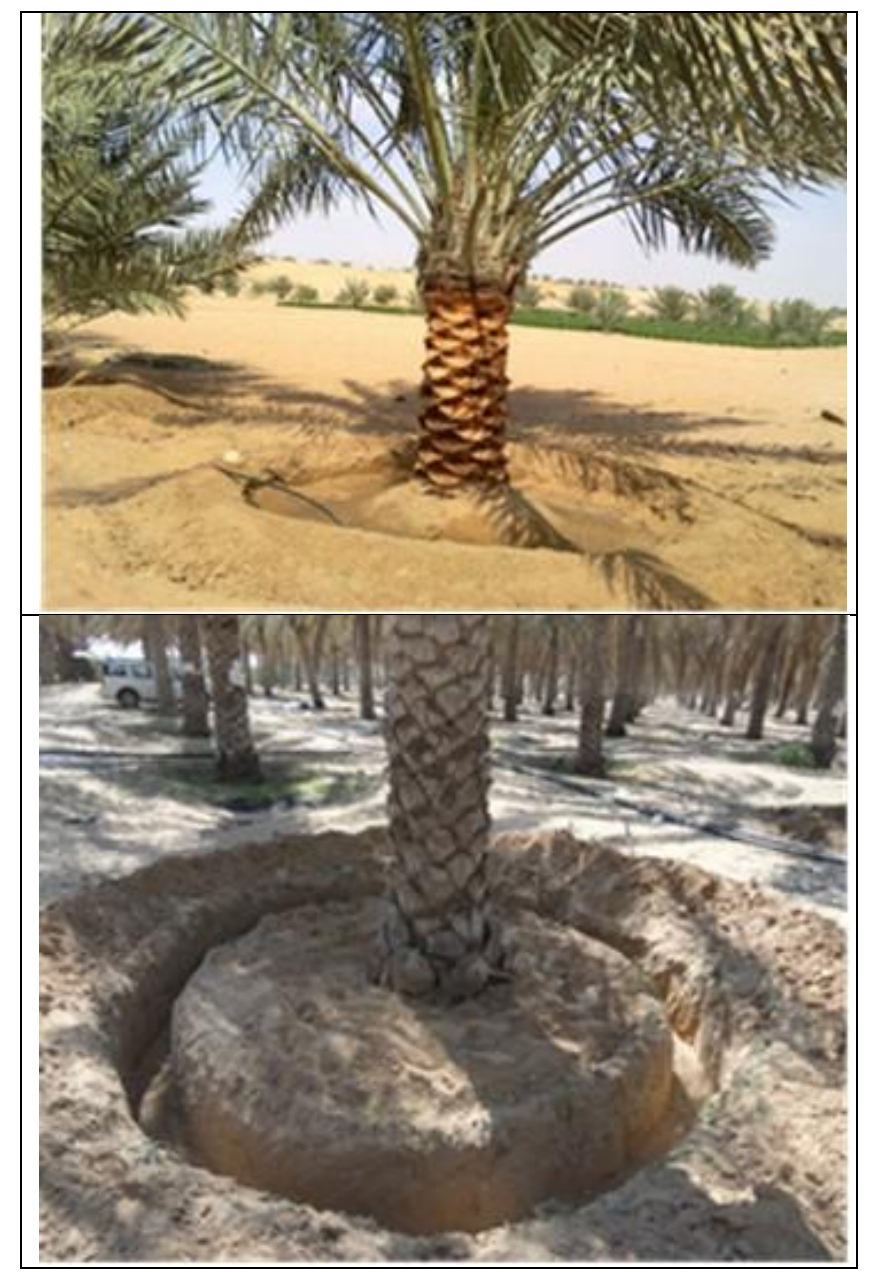

Figure 2. Sub-surface irrigation system.

Pruning- Pruning of date palm means removal of dead or nearly dead leaves and their bases when they also dried out. Is also possible to remove, green but broken leaves, and those attacks by serious pests.

Regular pruning and sanitation of date palm growing areas are critical for achieving prevention of pest infestation and disease infection. All dead leaves should be removed from the trees. To not provide a point of entry for pests, leaves should be cropped at the leaflet insertion area and the pruned area should be treated with pesticides. Pruning tools should be kept clean and disinfected as they can spread the fungal disease black scorch. This disease affects the flower and fruit strands which become deformed and causes terminal bud and trunk rot. It can eventually kill the trees (Dowson, 1982).
This operation aims also to facilitate cultivation operations: pollination, fruit thinning, bunch pending and dates harvesting (Hussain et al., 1984). Dead leaves and leaf bases growing up to the lower end of fruit bunch must be removed after harvest, as they don't drop off naturally.

This operation is not practiced by many growers because of the difficulty of climbing the date palm tree. Mechanization is now providing means to facilitate pruning without climbing date palm tree. Date palm leaves can be used for many different purposes. When moving leaves from region to region, attention must be not to spread pests such as date palm scale: Parlatoria blanchardi L. (Nixon and Carpenter, 1978).

When pruning date palm, attention is needed to use good materiel for cutting leaves and frond bases (Kernef). It is also recommended to select the proper time of pruning and practice it during the period of low insects and RPW activities.

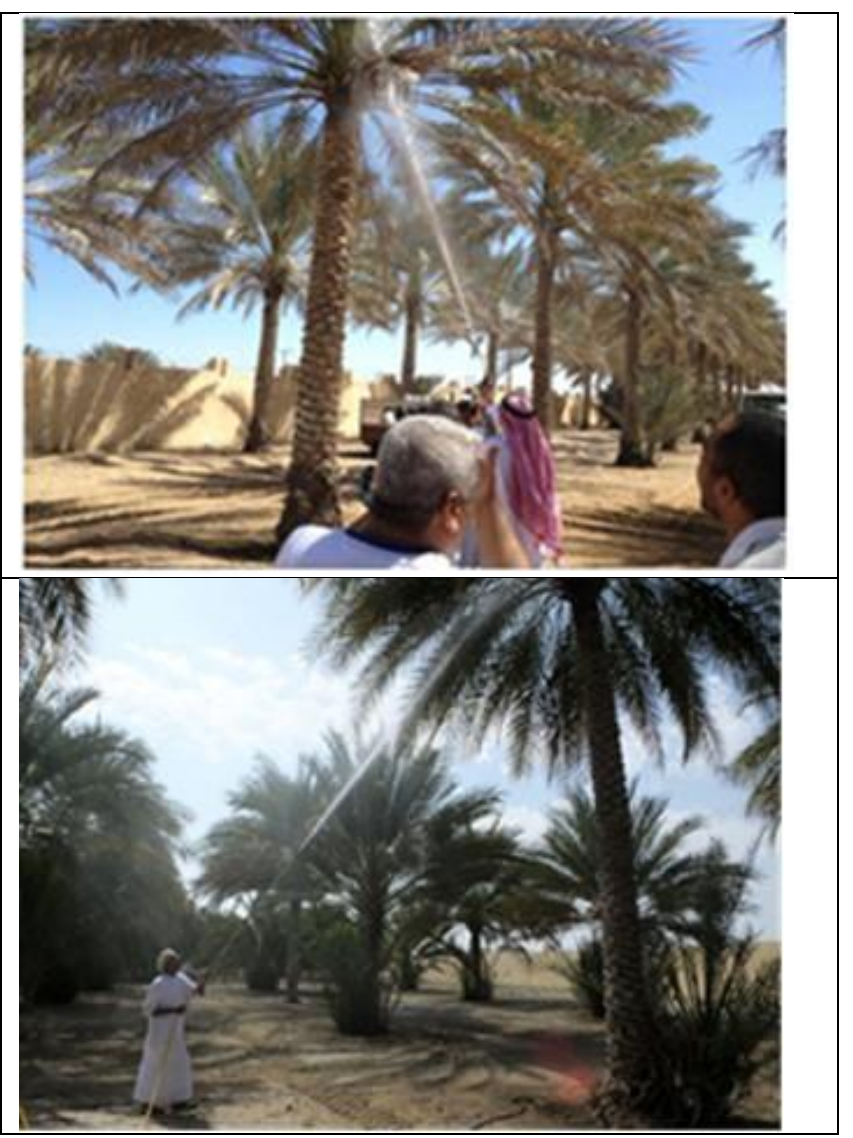

Figure 3. Date palm liquid pollination. 
تعرف أثجار نخيل التمر بحساسيتها العالية إزاء العمليات الزر اعية المطبقة؛ فتتناسب حالة الثجرة الصحيَّة وبالتالي إنتاجيتها مع مدى عناية المزارعين

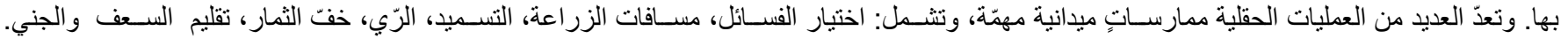

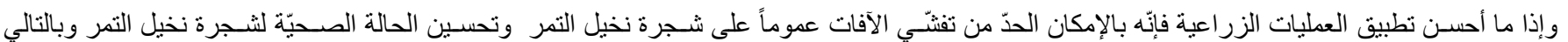

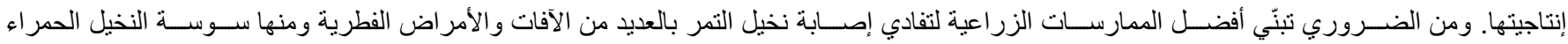
Rhynchophorus ferrugineus Olivier

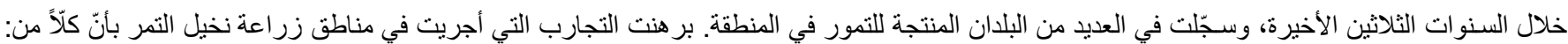
الممارسات الزراعية المتّبعة، الصنف المزروع، طريقة الري (غمر/تنقيط)، كثافة النخيل في وحدة المساحة، تطهير النخيل والمزر عة، تقليم السعف وفصل الفسائل،

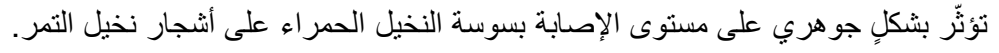

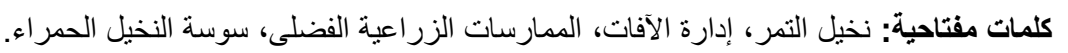

\section{References}

Ben Salah, M. 2018. Date palm field operations and their importance for reducing pest's infestation. Pages 161169. In: Date Palm Pests and Diseases Integrated Management Guide. M. El Bouhssini and J.R. Faleiro (eds.). Beirut, Lebanon: International Center for Agricultural Research in the Dry Areas (ICARDA), 2018. 181 pages.

Ben Salah, M. and M.H. El Marzooqi. 2000. Mechanization of date palm pollination using hand duster and machine in sultanate of Oman. OADA. Internal report.

Ben Salah, M. 1999. Technologic package to rehabilitate date palm in Saudi Arabia, Oman, Bahrain and Kuwait. Arab Organization for Agricultural Development (OADA). 1998.

Ben Salah, M. and Y. Al-Raisi. 2017. Liquid pollination: New field technique to enhance the date palm production. 2nd National Conference on Agriculture and Fisheries Research (Research for Sustainable Development). Sultan Qaboos University, MuscatOman. 3-4 April, 2017

Dewidar, Z.A., Y. Al-Fehaid, S. Al-Hilal and M. Ben Salah. 2016. Water saving in Arid Regions: A comparison of Surface and subsurface drip irrigation systems. American Journal of Innovative Research and Applied Sciences, 2: 289-296

Dowson, V.H.W. 1982. Date production and protection. UN-FAO Plant Production and Protection Paper 35. Rome.

El-Bekr, A. 1972. The date palms. A review of its past, present status and the recent advances in its culture industry and trade. Imp. El Ani. Bagdad. Iraq. 1050 p.
Faleiro, J.R. 2006. Insight in to the management of Red Palm Weevil (Rhynchophorus ferrugineus Olivier) Based on experiences on coconut in India and date palm in Saudi Arabia. Fundación Agroalimed. Jornada Internacional sobreel Picudo Rojo de las Palmeras. 2729 November 2005. Valencia, Spain. Pages 35-57

Hussain, F.A., S.M. Bader, M.T. Alqadi and E.N. Samarmed. 1984. Effect of pruning of date palm (Phoenix dactylifera L.) Zahdi cv., on some qualitative and quantitative characteristics of fruit. Date Palm Journal, 3: 33-43

ICARDA (International Center for Agricultural Research in the Dry Areas). 2016. Annual report of the project: Development of Sustainable Date Palm Production Systems in the GCC Countries of the Arabian Peninsula. $12 \mathrm{pp}$.

Klein, P. and A. Zaid. 2002. Land preparation, planting operation and fertilisation requirements. In: Zaid, A. Arias-Jimenez, E. J. Date palm cultivation. FAO plant production and protection paper, 156 rev.1. FAO, Rome

Liebenberg, P.T. and A. Zaid. 2002. Date palm irrigation. In: Date Palm Cultivation. A. Zaid and P.E. de Wet (eds.) FAO Plant Production and Protection Paper. 156. Food and Agricultural Organization of United Nations, Rome.

Nixon R.W. and J.B. Carpenter. 1978. Growing dates in the United States. USDA Information Bulletin 207. Washington, D.C.

Shabana, H.R., T.H. Khalil and I.A. Mawlood. 1985. Report of pollination mechanization project. Department of Palms and Dates, Agriculture and Water Resources Research Center, Baghdad, Iraq. 